\title{
The Mechanism of Signal Processing of Solar Radio Burst Data in E-CALLISTO Network (Malaysia)
}

\author{
Z. S. Hamidi ${ }^{1, *}$, N. N. M. Shariff ${ }^{2}$ \\ ${ }^{1}$ School of Physics and Material Sciences, Faculty of Sciences, MARA University of Technology, \\ 40450, Shah Alam, Selangor, Malaysia \\ ${ }^{2}$ Academy of Contemporary Islamic Studies (ACIS), MARA University of Technology, \\ 40450, Shah Alam, Selangor, Malaysia \\ *E-mail address: zetysh@salam.uitm.edu.my
}

\begin{abstract}
Solar space weather events like Coronal Mass Ejections and solar flares are usually accompanied by solar radio bursts, which can be used for a low-cost real-time space weather monitoring. In order to make a standard system, a CALLISTO (Compound Astronomical Low-cost Low-frequency Instrument for Spectroscopy in Transportable Observatory) spectrometers, designed and built by electronics engineer Christian Monstein of the Institute for Astronomy of the Swiss Federal Institute of Technology Zurich (ETH Zurich) have been already developed all over the world since 2005 to monitor the solar activities such as solar flare and Coronal Mass Ejections (CMEs). Up to date, there are 25 sites that used the same system in order to monitor the Sun within 24 hours. This outstanding project also is a part of the United Nations together with NASA initiated the International Heliophysical Year IHY2007 to support developing countries participating in 'Western Science'. Beginning February 2012, Malaysia has also participated in this project. The goals of this work is to highlight how does the signal processing of solar radio burst data transfer from a site of National Space Centre Banting Selangor directly to the Institute of Astrophysics Switzerland. Solar activities in the low region, focusing from $150 \mathrm{MHz}$ to $400 \mathrm{MHz}$ is observed daily beginning from 00.30UT 12.30 UT. Here, we highlighted how does the signal processing work in order to make sure that the operation is in the best condition. Although the solar activities have experienced rapid growth recently, high-level management of CALLISTO system has remained successfully manage the storage of data. It is also not easy to maintain the future data seems the number of sites are also growing from time to time. In this work, we highlighted the potential role of Malaysia as one of the candidate site that possible gives a good data and focusing on a few aspects such as optimization, and performance evaluation data and visualization.
\end{abstract}

Keywords: Space weather; CALLSITO system; ISWI (International Space Weather Initiative); Sun; solar radio burst; solar activity; signal processing; e-network

\section{INTRODUCTION}

Space weather is defined as a study of the conditions in the solar wind that can affect life on the surface of the Earth, particularly the increasingly technologically sophisticated devices that are part of modern life [1]. The solar space weather events like Coronal Mass Ejections and solar flares are usually accompanied by solar radio bursts, which can be used for a low-cost real-time space weather monitoring [2]. There are many reviews of the history 
of these phenomena, specifically, by Kundu [3] and McLean and Labrum [4] for observational reviews, Zheleznyakov [5], Melrose [6] and Benz [7] for the theory of radio emission in these bursts, and Pick [8] and Schwenn [9] for the relationship with space weather. Over periods of increased solar activity, several Coronal Mass Ejections (CMEs) can be launched by the same or nearby active regions [10]. It could not be denied that solar activities play a crucial role in global circulation and climate changes. Due to the fact, we focus a solar radio monitoring at low frequency region (45 MHz to $870 \mathrm{MHz}$ ). However, most of the solar radio flare signals are characterized by complex variability patterns including both non-stationarities and nonlinearities. In 2007, the United Nations together with NASA initiated the International Heliophysical Year IHY2007 to support developing countries participating in 'Western Science'. All activities of IHY2007 closed in 2009 by the UN office in Vienna, but immediately continued in the new project ISWI (International Space Weather Initiative), again supported by the UN and NASA. During the past years, many CALLISTO spectrometers have been deployed and set into operation in different countries all over the world [11]. These projects target to achieve two purposes:Firstly, the scientific objective of $24 \mathrm{~h} / 7 \mathrm{~d}$ coverage of solar observations; and, secondly, the political objective to support developing countries. Currently, there are more than 20 instruments are installed, whereas about 11 regularly supply data to the central archive in Switzerland. However, there are still some gaps in the Pacific region during winter-season.

In order to make a standard system, a CALLISTO (Compound Astronomical Low-cost Low-frequency Instrument for Spectroscopy in Transportable Observatory) spectrometers, designed and built by electronics engineer Christian Monstein of the Institute for Astronomy of the Swiss Federal Institute of Technology Zurich (ETH Zurich) have been already developed all over the world since 2005 to monitor the solar activities such as solar flare and Coronal Mass Ejections (CMEs). Initiated by Institute of Astrophysics Switzerland, there are 25 sites that used the same system in order to monitor the Sun within 24 hours. This system was particularly useful for studying the large explosions in the Sun's atmosphere known as solar flares. The radio emissions from these events are important for understanding the dynamics of the solar corona. This outstanding project also is a part of the United Nations together with NASA initiated the International Heliophysical Year IHY2007 to support developing countries participating in 'Western Science'. Beginning February 2012, Malaysia has also participated in this project [12]. The goals of this work is to highlight how does the signal processing of solar radio burst data transfer from a site of the National Space Centre Banting Selangor directly to the Institute of Astrophysics Switzerland. Based on this project, how to transfer and manage the data become an important role to be considered. In this case, signal processing that deals with operations on our analysis of signals, or measurements of time-varying or spatially varying physical quantities is required. We are interested a signal can include sound, images due to the specific range of frequency. We also concerned the noise of RFI sources, and analysis from continuously has been done [13]. In general, the allocation for radio astronomy are at the frequency of 13.36-13.41 MHz (solar), (25.55-25.67) $\mathrm{MHz}$ (Jupiter) and (37.50-38.25) MHz [14]. 


\section{THE RADIO FREQUENCY INTERFERENCE MONITORING AND THE CALLISTO SYSTEM}

Malaysia also involved this research since February 2012 and routinely monitor 12 hours per day at National Space Centre, Selangor [15]. We started by proposing this research in early 2011, through the National Space Agency of Malaysia (ANGKASA), University of Malaya (UM), MARA University of Technology (UiTM) and National University of Malaysia (UKM) [16]. Seems we are in the equatorial country, the range of temperature varied from $26-31^{\circ}$ Celcius throughout a year. Generally, the signal from the log periodic dipole antenna antenna is directed to the (Compound Astronomical Low-cost Low-frequency Instrument for Spectroscopy in Transportable Observatory) CALLISTO spectrometer, which is housed in a steel case, via a low loss coaxial cable, LMR-240 [17]. Similar to another site, the instrument holders have set up an FTP-server at their host-site with a local archive. All data are stored with a scale factor and an offset applied so that the measured ADC digits range fits into the byte data range $(0$ - 255) [18]. Figure 1 shows the location of our site and instrumentation setup of CALLISTO system.

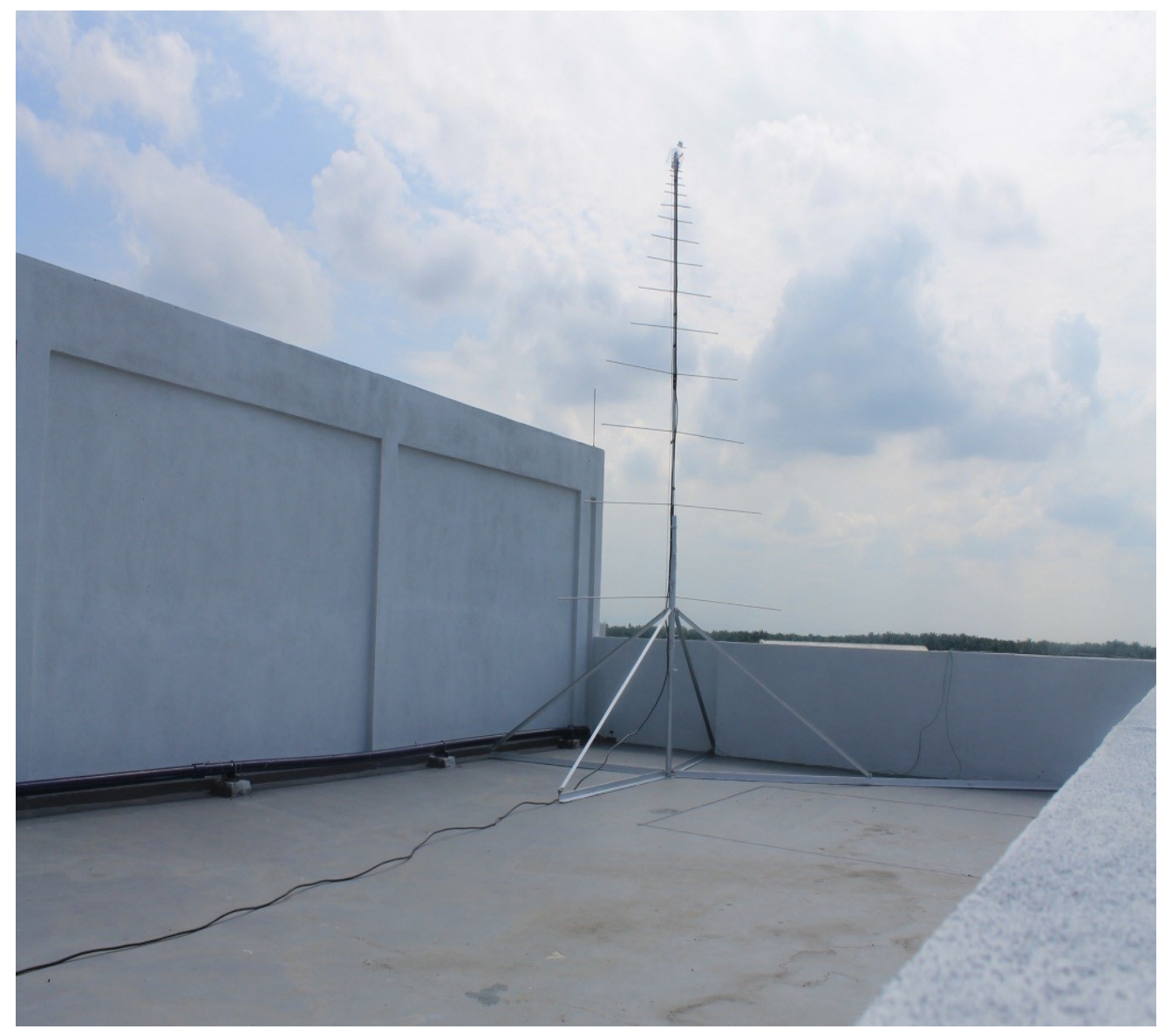

Figure 1. Location of our site and instrumentation setup of CALLISTO system.

In this work, at a preliminary stage, we detect the main RFI sources that need to remove effectively every time observations are taken (Z.S.Hamidi, 2012). First light detection of solar burst type IV in Malaysia in the region of $260 \mathrm{MHz}$ till $380 \mathrm{MHz}$ has been successfully detected on 5th March 2012 (Z.S.Hamidi, 2012). This significant solar burst variation is 
associated with solar flare type M level 2.0 occurred from 0412UT. Due to the effect, strong bursts that caused by extraordinary solar flares due to magnetic reconnection effect potentially induced in the near-Earth magneto tail. Once per day a cron-job (PERL) gets in contact with the instrument holder, reads the directory, selects files of interest and uploads them to the main server in Switzerland. Data will be saved based on the duration of period of daylight in Universal Time (UT) and compile every 15 minutes. All data can be achieved from e CALLISTO websites initiated by Institute of Astrophysics, Switzerland. This observational data are limited only a good range of frequency with minimum interference. In order to keep data only with high probability of containing solar radio flares, a filter method also be used from time to time. This data can also be compared with the National Oceanic and Atmospheric Administration (NOAA) list is in an updated state. Data archive allows to store up to 10 TeraBytes of FIT-files. The archive is physically located at FHNW (Fachhochschule Nordwestschweiz) and managed from ETH (Eidgenössisch Technisch Hochschule in Zurich).

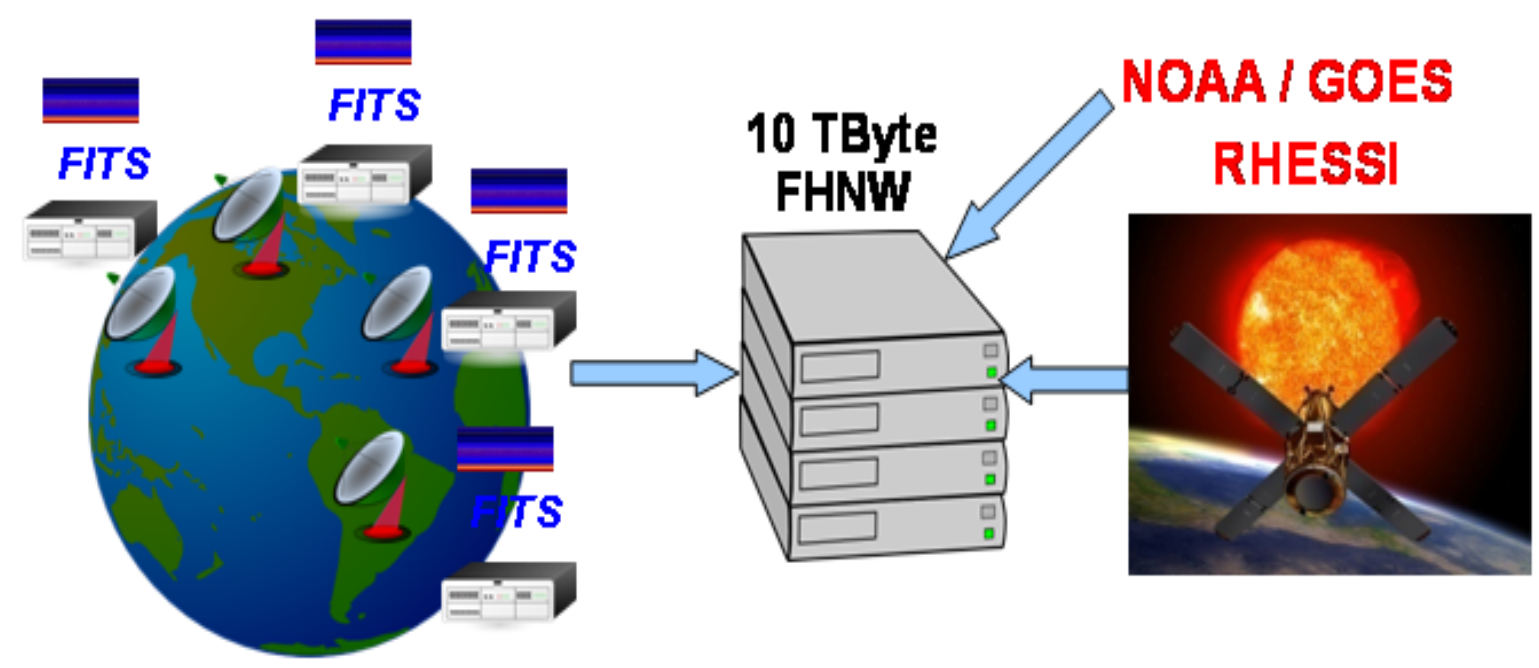

Figure 2. The Dataflow from observatories to the archive (Credited to C.Monstein, ETH Zurich, Switzerland).

There are a few software that helps to transfer the data, such as FTP-watchdog could replace a function of FTP server and make the process of the data can be automatically transferred into a table based on the timing of the solar activities. For the basic data reduction purpose, we can use a JAVA software to subtract the data from background noise. All data can be analyzed in detail with IDL (Interactive Data Language) program.

The solar with RFI monitoring should be done at the same time [19]. So far, we also have investigated the RFI at different altitude [20]. Our site has become the 19th site that participates the solar burst monitoring and an observational of Radio Frequency Interference (RFI) been done [21]. It should be noted that the Earth environment has a close connection with Sun activities [22]. Therefore, it is very important to study the solar radio burst data associated with solar flares and Coronal Mass Ejections (CMEs) [23-25]. These phenomena are due to the behaviour of the sunspots or active region [26]. The solar activities indirectly affected the conditions of earth's climate and space weather [27,28]. 


\section{RESULTS AND ANALYSIS}

Solar activities in the low region, focusing from $150 \mathrm{MHz}$ to $400 \mathrm{MHz}$ is observed daily beginning from 00.30UT 12.30 UT. Figure 3 shows the coverage of solar monitoring in Malaysia and the total of coverage of the e-CALLISTO network.
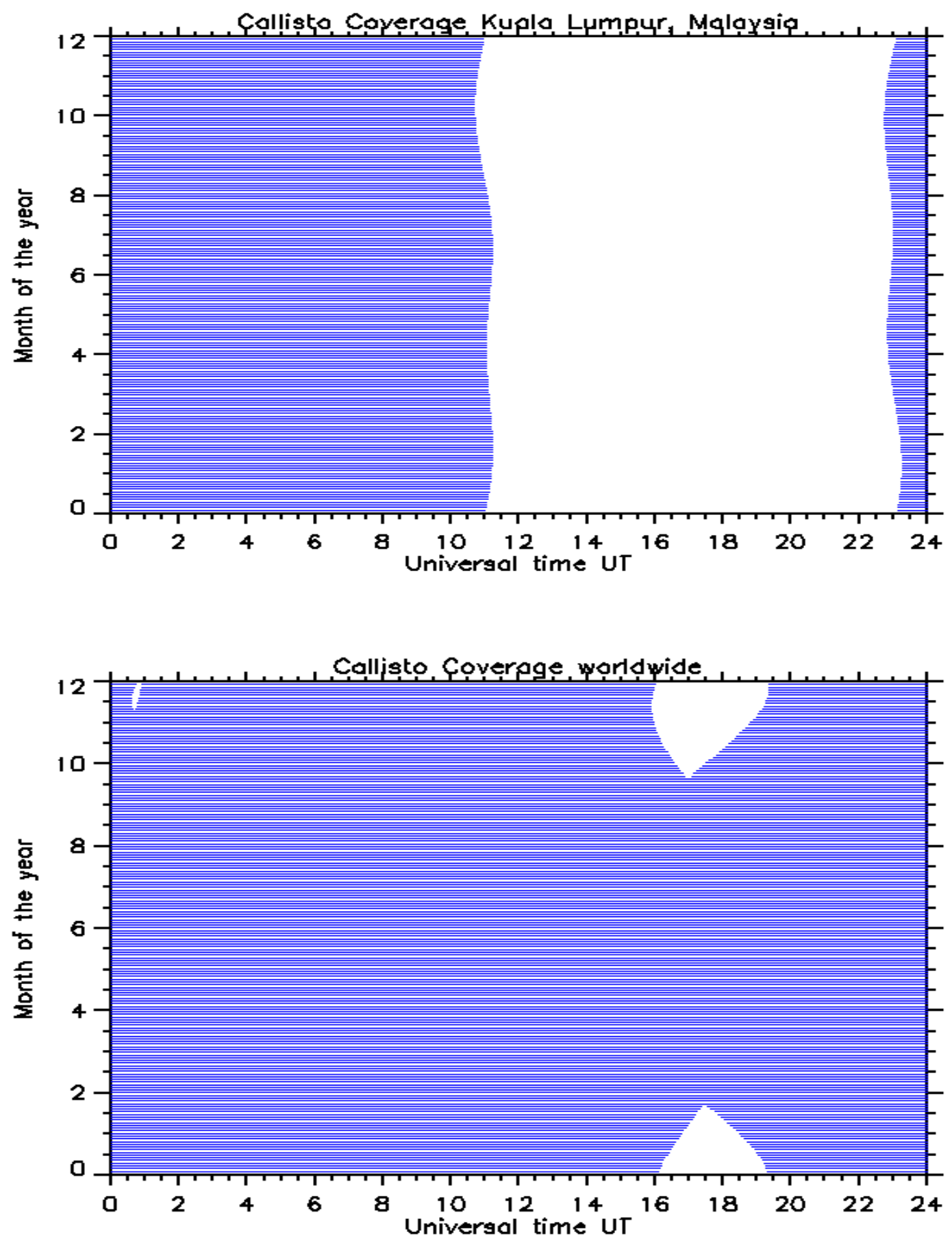

Figure 3. The coverage of solar monitoring in Malaysia and the total of coverage of e-

CALLISTO network. 
Up to date, this project has successfully achieved more than 90 percent target in order to monitor the Sun within 24 hours. Malaysia also contributed almost 50 percent of the daily data. In fact, we are the second earliest site that monitors a solar activity every day after Alaska. Moreover, we are also one of the equatorial sites that possible gives an early indicator in terms of solar variability. So far, we possible to contribute a good data.we found that we possible to detect solar burst type III almost every day if there is an active region. We hope that we could improve the system on a few aspects such as amplification of the signal, the storage of the data and also the technical part of the antenna. Figure 4 illustrates the schematic diagram the mechanism of signal processing of solar radio burst data of e-CALLISTO network.

\section{e-CALLISTO}

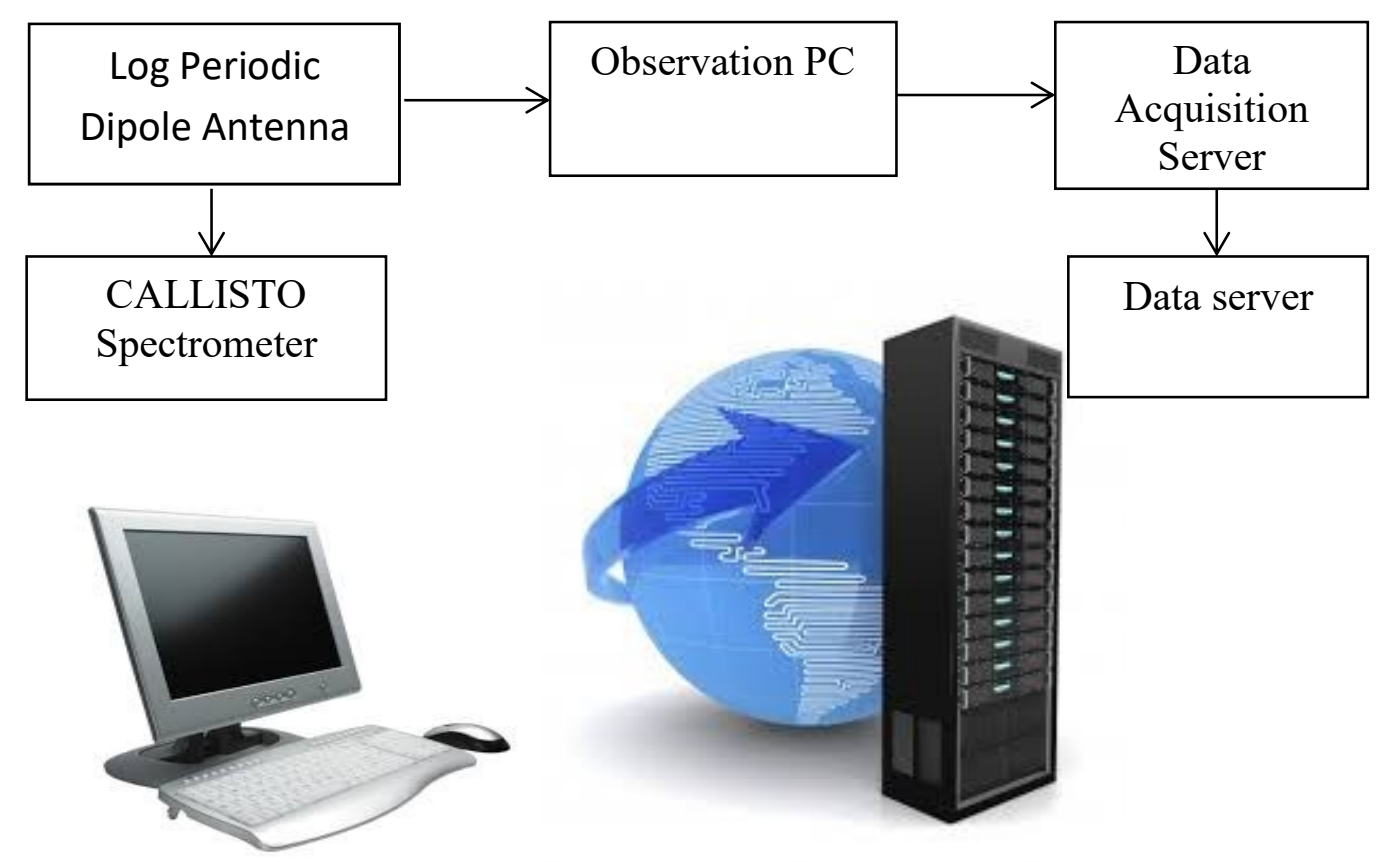

Figure 4. Schematic diagram of the monitoring system produced by the CALLISTO software and tracking software are transferred to the data acquisition server by the software.

\section{CONCLUDING REMARKS}

Although the solar activities have experienced rapid growth recently, high-level management of CALLISTO system has remained successfully manage the storage of data. Further actions need to be taken to prove solar monitoring studies are very important and should be extended. As sensing and monitoring technology continues to improve, there is an opportunity to deploy sensors in this system in order to improve their management. It is also not easy to maintain the future data seems the number of sites are also growing from time to time. In this work, we highlighted the potential role of Malaysia as one of the candidate sites that possible gives a good data and focusing on a few aspects such as optimization, and performance evaluation data and visualization. Our next plan is to discover the potential for dynamic optimization of an array's of antenna with a focus on mitigation of fault conditions 
and optimization of power output under non-fault conditions. Finally, monitoring system design considerations such as the type and accuracy of measurements, sampling rate, and communication protocols are considered. It is our hope that the benefits of monitoring presented here will be sufficient to offset the small additional cost of a sensing system, and that such systems will become common in the near future.

\section{Acknowledgement}

We are grateful to e-CALLISTO network that makes their data available online. This work was partially supported by the FRGS (600 RMI/FRGS 5/3 2012) UiTM grants. Special thanks to the National Space Agency and the National Space Centre for giving us a site to set up this project and support this project. Solar burst monitoring is a project of cooperation between the Institute of Astronomy, ETH Zurich, and FHNW Windisch, Switzerland, MARA University of Technology and University of Malaya. This paper also used NOAA Space Weather Prediction Centre (SWPC) for the sunspot, radio flux and solar flare data for comparison purpose. The research has made use of the National Space Centre Facility and a part of an initiative of the International Space Weather Initiative (ISWI) program.

\section{Biography}

Dr. Zety Sharizat Hamidi is currently a senior lecturer and focused in Solar Astrophysics research specifically in radio astrophysics at the School of Physics and Material Sciences, Faculty of Sciences, MARA University of Technology, 40450, Shah Alam, Selangor, Malaysia. Involve a project under the International Space Weather Initiative (ISWI) and also a lecturer in School of Physics and Material Science, at MARA University of Technology, Shah Alam Selangor.

Dr. Nur Nafhatun Md Shariff is a senior lecturer in Academy of Contemporary Islamic Studies (ACIS), MARA University of Technology, 40450, Shah Alam, Selangor, MalaysiaHer current research is more on sustainability; environmental aspect. She is looking forward for cross-field research, i.e. solar astrophysics, light pollution measurement (mapping) and religious studies.

\section{References}

[1] S.M. White, Solar Radio Bursts and Space Weather, Asian Journal of Physics 16 (2007) 189-207.

[2] V.V. Lobzin, C. I.H., R. P.A., S. G., G. Patterson, Automatic recognition of type III solar radio bursts; automated radio burst identification system method and first observations, Space Weather (2009).

[3] M.R. Kundu, Solar Radio Astronomy, John Wiley, 1965.

[4] D.J. McLean, A.N.R. Labrum, Solar Radiophysics, Cambridge University Press, Cambridge, 1985.

[5] V.V. Zheleznyakov, Radio Emission of the Sun and Planets (1970).

[6] D.B. Melrose, Plasma Astrophysics., Gordon and Breach, New York, 1980.

[7] A.O. Benz, Solar and Stellar Coronae, Kluwer Academic Publishers, 2002.

[8] M. Pick, Solar and Space Weather Radiophysics., in: D.E. Gary, C.U. Keller (Eds.), Dordrecht, 2004, pp. 17-45. 
[9] R. Schwenn, Space Weather: The Solar Perspective, Living Rev. Solar Phys. 3 (2006).

[10] N. Gopalswamy, E. Aguilar-Rodriguez, S. Yashiro, S. Nunes, M.L. Kaiser, R.A. Journal of Geophysical Research 110 (2005).

[11] A.O. Benz, M. Guedel, H. Isliker, S. Miszkowicz, W. Stehling, A broadband Sol. Phys. 133 (1991) 385-393.

[12] Z. Hamidi, N. Shariff, Z. Abidin, Z. Ibrahim, C. Monstein, E-Callisto Collaboration: Some Progress Solar Burst Studies Associated with Solar Flare Research Status in Malaysia, (2012).

[13] Z.S.Hamidi, Z. Abidin, Z. Ibrahim, C. Monstein, N. Shariff, International Journal of Fundamental Physical Sciences 2 (2012) 32-34.

[14] Z. S. Hamidi, N. N. M. Shariff, C. Monstein, W. N. A. Wan Zulkifli, M. B. Ibrahim, N. S. Arifin, N. A. Amran, International Letters of Natural Sciences 5 (2014) 10-17

[15] Z. Hamidi, N. Shariff, C. Monstein, First Light Detection of A Single Solar Radio Burst Type III Due To Solar Flare Event, (2014).

[16] Z.S.Hamidi, Z. Abidin, Z. Ibrahim, N. Shariff, Indication of radio frequency interference (RFI) sources for solar burst monitoring in Malaysia, ICPAP 2011, AIP Publisher, Indonesia, 2012, pp. 6.

[17] N. Anim, Z.S. Hamidi, Z.Z. Abidin, C. Monstein, N. Rohizat, Radio frequency interference affecting type III solar burst observations, PERFIK 2012, AIP Publisher, Pahang Malaysia, 2012, pp. 5.

[18] R. Umar, Z.Z. Abidin, Z.A. Ibrahim, M.S.R. Hassan, Z. Rosli, Z.S. Hamidi, Population density effect on radio frequencies interference (RFI) in radio astronomy, AIP Conference Proceedings 1454 (2012) 39.

[19] Z.S.Hamidi, N.N.M.Shariff, Evaluation of Signal to Noise Ratio (SNR) of Log Periodic Dipole Antenna (LPDA) Business Engineering and Industrial Applications Colloquium 2013, IEEE, Langkawi, Malaysia, 2013, pp. 434-438.

[20] R. Umar, Z. Abidin, Z. Ibrahim, N. Gasiprong, K. Asanok, S. Nammahachak, S. Aukkaravittayapun, P. Somboopon, A. Prasit, N. Prasert, Middle East Journal of Scientific Research 14 (2013).

[21] Z.S. Hamidi, N. Shariff, Z. Abidin, Z. Ibrahim, C. Monstein, Middle-East Journal of Scientific Research 12 (2012) 6.

[22] Z.S. Hamidi, N.N.M. Shariff, C. Monstein, Z. Abidin, Z. Ibrahim, N. Hashim, R. Umar, N. Aziz, International Journal of Fundamental Physical Sciences 3 (2013) 57-63.

[23] Z.S.Hamidi, N.M.Anim, N. N.S.Hakimi, N.Hamzan, A.Mokhtar, N.Syukri, S.Rohizat, I.Sukma, Z.A. Ibrahim, Z.Z.Abidin, N.N.M.Shariff, C.Monstein, International Journal of Fundamental Physical Sciences 2 (2012) 4.

[24] Z.S.Hamidi, Z. Abidin, Z. Ibrahim, N. Shariff, C. Monstein, Observations of coronal mass ejections (CMEs) at low frequency radio region on 15th April 2012, in: R.Shukor (Ed.), PERFIK 2012, American Institute of Physics, Malaysia, 2013, pp. 5.

[25] Z.S. Hamidi, N. Anim, N.N.M. Shariff, Z.Z. Abidin, Z.A. Ibrahim, C. Monstein, Dynamical structure of solar radio burst type III as evidence of energy of solar flares, in: R.Shukor (Ed.), PERFIK 2012, American Institute of Physics, Malaysia, 2013, pp. 11-15. 
[26] Z.S. Hamidi, N.N.M. Shariff, F.N.Z. Ulum, Z.Z. Abidin, Z.A. Ibrahim, International Journal of Astronomy 5 (2012) 101-106.

[27] Z.S. Hamidi, N.N.M.Shariff, C.Monstein, Z.A. Ibrahim, International Letters of Chemistry, Physics and Astronomy 7 (2014) 37-44.

[28] N. Hashim, Z. Abidin, U. Ibrahim, R. Umar, M. Hassan, Z. Rosli, Z. Hamidi, Z. Ibrahim, Radio Astronomy in Malaysia: Current Status and Outreach Activities, Astronomical Society of the Pacific Conference Series, 2011, pp. 355. 